\title{
Quelles cultures, pour quelles communautés ?
}

\author{
Jean-Pierre Vidal ${ }^{1}$ \\ Université du Québec à Chicoutimi
}

Perhaps the only significant dividing line [...] is the line between organizations that allow this diversity to flourish and those that try to stifle it. The latter runs the risk of losing competitiveness, because they restrict the pool of creative talent from which they can draw. Cities and regions also may lose competitiveness if they do not reflect the new culture.

Richard Florida $^{2}$

Toute la question de la place de la culture en région tient peut-être en une image, celle que des milliers de Chicoutimiens peuvent voir chaque jour lorsqu'ils passent devant la Pulperie, cette friche industrielle dont le recyclage culturel relativement récent n'a pas cessé d'alimenter les débats les plus passionnés et de provoquer les actions les plus inconsidérées; une affiche du gouvernement du Québec y proclame fièrement: "Agir pour la culture, c'est soutenir le tourisme culturel à Saguenay ».

Même en faisant abstraction de l'aspect réducteur, et pour tout dire assez insultant, d'une affirmation digne du concept de réserve (venez voir les indigènes à l'œuvre) qui ne fait que perpétuer dans un autre registre l'idée, ô combien dommageable, de " région ressource », cette formule est fautive à plus d'un titre. Je m'efforcerai dans les lignes qui suivent de montrer pourquoi.

Remarquons d'entrée de jeu que le rôle économique de la culture, abondamment démontré depuis plusieurs années mais systématiquement méconnu et par les décideurs et par le grand public, se trouve ici réduit à celui d'attracteur: la culture, c'est payant, comme un paysage, quand ça fait venir le chaland. Et il est vrai que la tendance générale de l'époque de massification accélérée que nous connaissons pousse à une conception utilitaire de la culture où le public n'est qu'un consommateur, pressé et sans compétences critiques, auquel on donne des distractions à effet immédiat et faciles à digérer. Produit de consommation courante comme un autre - on reconnaîtra là, et ce n'est pas un hasard, la position officielle des ÉtatsUnis d'Amérique dans toutes les négociations tendant à libéraliser encore plus le commerce mondial - la culture ne se rêve universelle que dans la mesure où elle répondrait à un besoin clairement identifié de se distraire, c'est-à-dire de se sortir de ce qui constitue normalement sa vie. Il s'agit ainsi tout naturellement d'une culturemédium, une sorte d'environnement sans caractère, aussi normalisé et mondialisé que le travail pris dans son sens le plus élémentaire de tâche plus ou moins intéressante et passablement répétitive, un simple gagne-pain qui assure survie et, si possible, confort. La culture n'est qu'un de ces loisirs que le capital octroie au travail pour qu'il renouvelle ses forces. Plus $\mathrm{XIX}^{\mathrm{e}}$ siècle que ça comme conception, tu préconises le port de la redingote !

Or, si l'émergence de la société du savoir n'est pas un mythe complaisamment entretenu par les médias, c'est d'abord et avant tout la nature du travail et le profil humain de ceux qui l'accomplissent qui va changer. Et cette déjà vieille conception de la culture comme divertissement et loisir risque de s'en trouver radicalement mise en cause. Ne voit-on pas déjà apparaître sur le front des nouvelles technologies une race de travailleurs dont la culture particulière infléchit la forme même de l'entreprise qui les emploie ? 
Mais la culture, au fond, qu'est-ce à dire ? Et en quoi peut-elle avoir sur l'économie un impact qui puisse s'étendre au-delà de la simple retombée ou de la fonction d'appât ? En quoi peut-elle être le moteur par excellence de toute économie du savoir?

\section{Vous avez dit « culture »?}

On a assisté récemment, surtout depuis les années 1980 , c'est-à-dire l'émergence du néo-libéralisme et de l'individualisme de masse induit par le type de consommation qu'il a créée, à un glissement du sens du mot «culture » vers une définition presque uniquement anthropologique et sociologique. Autrement dit, on est passé d'une définition insistant sur la production, l'effort, le procès - l'idée traditionnelle de culture comme acquisition d'un certain nombre de connaissances qui transforment l'individu et la collectivité, idée inséparable, on le remarquera, des notions d'instruction et d'éducation - à une définition mettant de l'avant un ensemble de pratiques qui, pour être sociales, c'est-à-dire, il va de soi, créées de toutes pièces, n'en paraissent pas moins « naturelles » parce qu'elles sont l'émanation manifeste et pour ainsi dire inévitables d'une collectivité donnée. Comme jadis M. Jourdain et sa prose, on fait de la culture sans le savoir, rien qu'en existant en société.

Je ne discuterai pas ici de la pertinence de ce dernier type de définition à l'intérieur des champs disciplinaires des sciences humaines où il a acquis une efficacité opératoire indéniable. Je ferai simplement remarquer que sa prévalence (et même son exclusivité) dans le discours des médias sert essentiellement à donner une légitimité à un type de culture que l'on nomme, pour cette raison même qu'elle se donne comme la seule possible, "populaire », alors qu'elle est d'abord et avant tout " industrielle», certains artistes diraient « commerciale » et les ados « bourgeoise ».

Cette dernière appellation aura d'ailleurs ici le mérite de me permettre d'introduire les recherches de l'auteur de mon exergue, Richard Florida, professeur en développement économique régional à l'université Carnegie Mellon de Pittsburgh. Son nom est attaché à l'invention de l'indice « bohémien », un des éléments essentiels dans la mesure de l'attractivité d'une ville ou d'une région non pas pour la clientèle, par définition transitoire et intermittente, des touristes, mais pour les entreprises d'avenir, celles qui appartiennent

à ce qu'il appelle la Creative Economy, autre nom de l'économie du savoir dont il va de soi que les industries (extractives ou, au mieux, de première transformation) qu'on s'obstine à vouloir sauver dans certaines régions menacées n'en font absolument pas partie.

\section{Les compagnies émergentes sont attirées par les villes et les régions où existe ce type de milieu effervescent sur le plan intellectuel et culturel, plutôt que par des incitatifs fiscaux, des ressources naturelles ou une main-d'œuvre bon marché.}

La Bohème dont il s'agit ici n'est pas la région d'Europe centrale que notamment son cristal a rendue célèbre, c'est plutôt celle de l'opéra de Puccini ou de la chanson d'Aznavour, c'est-à-dire un mode de vie « artiste », fait de créativité, d'insouciance, de plaisir et d'un certain dandysme anti-bourgeois, bourgeois voulant dire ici, comme dans le langage des adolescents, rangé, timoré, conformiste. Un mode de vie qui a longtemps rimé avec misère et qui, en ce sens, correspond bien encore au niveau de vie de la plupart des artistes professionnels du Québec, comme une récente étude vient encore de le démontrer. Mais un mode de vie où l'horizon ne se borne pas à la rentabilité immédiate, à la baisse des taxes ou à l'abaissement de tous les niveaux de gouvernement au rôle de simples pourvoyeurs de services « livrant la marchandise » et en donnant aux «contribuables » (et le citoyen, lui ?) « pour leur argent ».

Or, l'indice bohémien de Florida semble prouver que les compagnies émergentes (les fameuses start-ups des Français) sont attirées par les villes et les régions où existe ce type de milieu effervescent sur le plan intellectuel et culturel $^{3}$, plutôt que par des incitatifs fiscaux, des ressources naturelles ou une maind'œuvre bon marché. Sur ce dernier point d'ailleurs, on peut faire remarquer que les pays où, à l'heure actuelle, la mondialisation fait atterrir les délocalisations d'entreprises qui nous coûtent tant d'emplois, et de haut niveau, l'Inde, bientôt la Chine et demain vraisemblablement les pays d'Europe centrale de l'ancien bloc communiste, sont soit des pays de fort ancienne culture (et de culture savante), soit des pays où, pour des raisons sans doute de propagande, l'État 
a toujours eu un souci officiel des arts, de la culture et de l'éducation. Sans nier les ravages et l'insigne pauvreté de l'art officiel du stalinisme et les difficultés innombrables et parfois graves qu'il a causées aux artistes, on n'oubliera pas la vaste entreprise de recherche et de développement des talents à laquelle s'est livré l'État soviétique et qui fait que maintenant, près de vingt ans après son effondrement, toutes les scènes du monde sont occupées par ses danseurs, ses chanteurs et ses virtuoses du piano ou du violon, entre autres. Pauvres mais riches en talents humains, tels sont ces pays qui vont bientôt nous damer le pion à nous qui sommes riches mais mettons un point d'honneur, dans notre système d'enseignement comme dans nos médias et nos politiques, nationales ou municipales, à appauvrir ou à décourager les talents que nous pouvons avoir.

Parce que nous avons choisi et choisissons encore la culture «populaire» contre la culture «élitiste », c'est-à-dire, pour parler net, l'entertainment et le show-bizz, la culture Québécor en un mot, contre la seule chose qui mérite le nom de culture parce qu'elle met en jeu naturellement, et pour tous ses acteurs, cette fameuse "croissance personnelle » dont gourous new-age et pop-psychologues nous rebattent sans cesse les oreilles, comme d'une mystique de quatre sous.

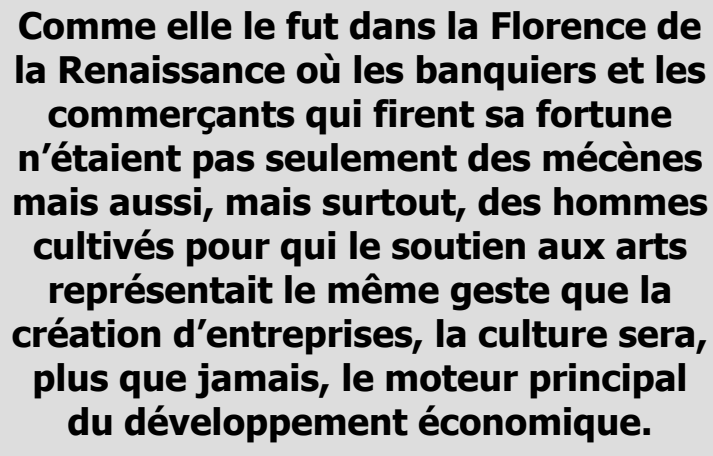

Car comment mettre en place une "société et une économie du savoir» dans un environnement qui valorise l'ignorance, la perte de mémoire et la standardisation (le format, comme on dit à la radio, à propos des chansons qui passent et de celles... qui ne passeront jamais) qui forment les traits caractéristiques de la culture abusivement dite populaire et qu'il serait plus juste de dire « de masse »?
Nous touchons ici au cœur de la question de l'impact économique direct de la culture, c'est-à-dire non pas ses retombées mais son pouvoir de création : dans la société du savoir, avant de créer des entreprises, il va falloir, en effet, créer des idées. Car non seulement les idées sont un savoir, mais il n'est pas d'idées sans savoirs. C'est un des mythes les plus soigneusement entretenus par les médias contemporains que les idées et la créativité puissent surgir sur une terre en friche, sur une humanité inculte. Et c'est, curieusement, une des retombées du marxisme le plus sommaire que de penser, comme le fait l'économiste américain moyen, de nos jours, que la superstructure culturelle dépend " en dernière instance », comme disait le philosophe marxiste Althusser, de l'infrastructure économique. Produisons, créons des jobs, et la culture, comme les autres aménités de la vie (dont les droits de l'homme et la liberté individuelle, disent les politiciens nationaux), suivront d'elles-mêmes. Il faut être aveugle comme un politicien, surtout municipal, pour ne pas voir les démentis flagrants apportés jour après jour par les faits à cette thèse.

Comme elle le fut dans la Florence de la Renaissance où les banquiers et les commerçants qui firent sa fortune n'étaient pas seulement des mécènes mais aussi, mais surtout, des hommes cultivés pour qui le soutien aux arts représentait le même geste que la création d'entreprises, la culture sera, plus que jamais, le moteur principal du développement économique. Si du moins la fameuse économie du savoir n'est pas un simple bobard médiatique inventé par des futurologues jovialistes.

Mais, au fait, à quoi tient ce pouvoir ?

\section{Culture et inculture}

La culture, entendue dans quel que sens qu' on veuille, est un processus d'arrachement. Un double arrachement: d'une part, d'avec les conditions minimales d'existence qu'il faut dépasser pour accéder à une humanité qui peut se penser elle-même comme telle; d'autre part et sans doute en même temps, un arrachement d'avec le groupe voisin puisqu'il n'est pas, dans quel que mythe que ce soit, d'image de fondation sans sacrifice de l'autre, qu'il s'appelle Abel ou Rémus. Pas de culture sans discernement, sans distinction, dans tous les sens du mot. Et la violence que dit le mythe est surtout celle de tout processus d'arrachement: il faut tuer le vieil homme en soi, 
liquider l'ignorance, mettre à mort l'immobilisme naturel à l'animal humain. Sans les artistes qui tapissaient ses cavernes, l'homme préhistorique n'en serait, justement, jamais sorti; c'est une autre des leçons qu'on peut tirer du fameux mythe platonicien. Sans ceux qu'on appelle, avec condescendance, des «pelleteux de nuages », l'humanité n'aurait probablement jamais inventé... le parapluie. Comme l'écrit Fernand Dumont: «Il y a culture parce que les personnes humaines ont la faculté de créer un autre univers que celui de la nécessité. Le langage en est la plus haute incarnation. Nous parlons pour dépasser le déjà-là, pour accéder à une conscience qui transcende le corps comme chose et autrui comme objet $\gg{ }^{4}$.

Dans la culture se mettent ainsi en jeu un rapport à l'autre et un rapport au monde (et donc au temps, dont l'histoire n'est que l'humanisation) dont la forme qu'ils peuvent prendre définissent une société, nul ne le niera. Ces deux rapports, qui en fait n'en font qu'un, le rapport du soi, individuel ou collectif, à l'autre, individuel ou collectif mais aussi humain et non humain, ce rapport, donc, peut être dynamisé, et c'est la culture dite à tort «élitiste » ou savante et qu'il faudrait dire plutôt « de recherche ». Ce rapport peut être, au contraire, fossilisé, et c'est la culture dite à tort « populaire ».

Bien sûr, pour se rendre compte de cette distinction, il faut savoir traverser le discours réducteur des médias et, par exemple, reconnaître que la diversité dont se vante la culture de masse est en fait l'apanage, et l'apanage exclusif, de la culture « élitiste » que j'appellerai dorénavant la culture, tout simplement, car l'autre n'est qu'une inculture... vendeuse. En veut-on un indice ? Chaque fois qu'un musicien " classique » passe dans les médias, on lui demande, avec un ton qui laisse à penser qu'il vaut mieux pour lui qu'il réponde par l'affirmative, s'il écoute un autre genre de musique. Sous-entendu : " ouvrez-vous ». Avezvous jamais entendu cette question posée à une vedette de la musique populaire? Sous-entendu : sa popularité est garante de sa diversité. Comme si la masse avait, en tant que masse (et non en tant que regroupement d'individus), la moindre ouverture, le moindre discernement. Mais la masse, le sociologue Jean Baudrillard l'a bien montré, notamment dans $L a$ société de consommation et $A$ l'ombre des majorités silencieuses, est réfractaire au symbolique et à la production du sens (d'où son apolitisme fondamental) : la masse ne veut que... faire masse. Le cancer média- tique et «culturel » de la téléréalité et des entreprises d'adulation familiale (on «sauve » «sa » future vedette pour en faire la «star» de tous) du genre Star Académie ou Canadian Idol, le démontre avec une évidence criante.

Les médias modernes induisent en effet la démagogie aussi sûrement que le théâtre grec était lié à la démocratie. Là où celui-ci visait à produire des citoyens, c'est-à-dire des individus capables de discerner, d'évaluer et de travailler sur soi autant que sur les autres et l'environnement, celle-ci travaille délibérément à produire de la masse, c'est-à-dire un volume de consommateurs évalué en termes de cotes d'écoute, autant dire de valeur marchande.

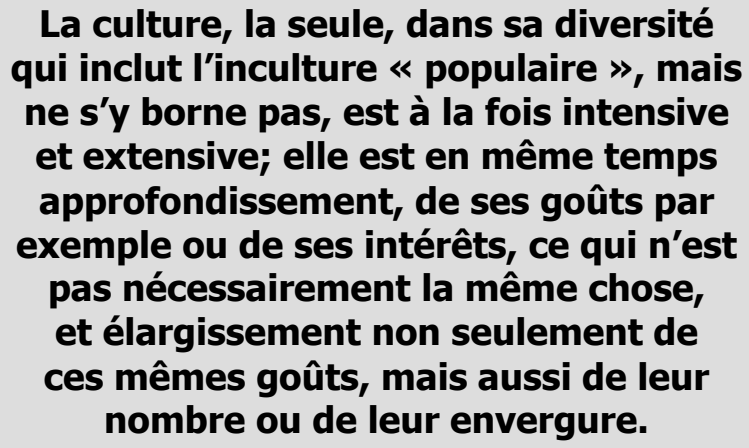

C'est pour cette raison que la culture - ou plutôt l'inculture - « populaire » ou de masse reste ponctuelle, répétitive, sans approfondissement, commandée exclusivement par l'offre qu'on lui fait, le produit qu'on lui fourgue et qu'on la convainc, vite fait bien fait, d'aimer. Parce qu'elle est sans histoire, restreinte à l'immédiateté d'un plaisir sans complication, un plaisir qui n'est jamais à conquérir mais toujours « donné », l'inculture populaire est un simple adjuvant, un dommage collatéral, une compensation pour une vie difficile, quelque chose comme le Prozac de l'esprit. Limitée à des goûts qui ne changent pas, ou sinon avec la lenteur des grands glaciers, elle refuse toute altération comme toute alternative.

Au contraire, la culture, la seule, dans sa diversité qui inclut l'inculture " populaire », mais ne s'y borne pas, est à la fois intensive et extensive; elle est en même temps approfondissement, de ses goûts par exemple ou de ses intérêts, ce qui n'est pas nécessairement la même chose, et élargissement non seulement de ces mêmes goûts, mais aussi de leur nombre ou de leur 
envergure. Nul ne saurait être dit cultivé s'il n'est pas, au moins partiellement, au fait de toutes les activités humaines, y compris, bien sûr la science, qui compose l'action symbolique de l'humanité sur le monde. Si l'inculture " populaire » ne vit que de répétitions, jusqu'à l'hébétude, de reconduction du même dans un narcissisme forcené (il faut à toute force que tout soit non seulement «à votre portée » mais vous parle de vous), de fermeture à peu près totale à ce qui n'est pas la très restreinte envergure de son petit soi, individuel et collectif, la vraie culture, elle, ratisse tout le champ de l'expérience humaine. Elle suppose (et crée) le discernement quand la culture de masse ne poursuit que l'assimilation, ne vise que la communion aveugle, le nombre indistinct.

La vraie culture est la prise en compte mais aussi en charge de toute l'expérience historique de l'humanité, non pas de façon scolaire, mais là encore de façon discriminée. Si l'homme cultivé tend à connaître ce qu'ont fait, dans les divers domaines de l'art et de la culture, les siècles précédents, il sait préférer tel ou tel siècle, tel ou tel créateur, telle ou telle forme d'art, telle ou telle tendance, tel ou tel mouvement. Et il sait les réinvestir, les faire jouer dans son siècle à lui de façon, d'une part, à les rendre plus neufs, d'autre part à faire paraître plus aigu son propre présent : car la culture est comme un révélateur chimique. Elle révèle à lui-même tout regard : ce que je suis capable de voir me dit ce que je suis, et réciproquement. Et l'ouverture de mon regard ouvre au monde la totalité de mon être.

Il y aurait bien d'autres choses à dire sur ce qu'est le dynamisme de la culture (par opposition à la fossilisation de l'inculture qu'on nous vend à pleine télé), mais l'espace m'est ici compté, et il me faut conclure, en revenant à l' « indice bohémien » de Florida.

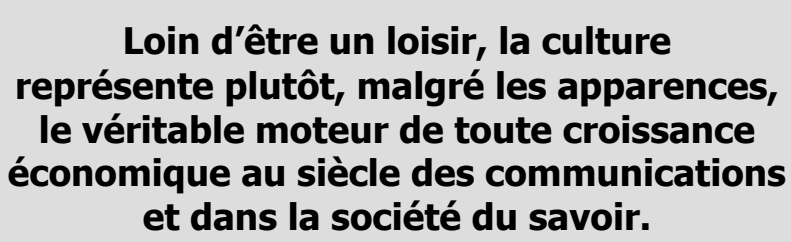

\section{La culture, mode de vie créatif}

Dans le livre auquel je me suis référé tout au long de cet article, Richard Florida se borne à constater la ten- dance des entreprises créatives à rechercher les personnes ressources dont elles ont besoin, les «bohémiens », lesquels bohémiens ont tendance, mobiles qu'ils sont parce que le travail vient à eux plus qu'il ne vont à lui, à s'installer là où sont les artistes et les vies culturelles intenses. Il se contente d'identifier la « classe créative », dont son livre salue l'émergence, par sa propension à rechercher des milieux créatifs déjà existants.

J'ai tenté brièvement ici, pour ma part, d'aller un peu plus loin que cette logique du « qui se ressemble s'assemble » en proposant quelques-unes des raisons qui semblent la mettre en branle. Ce faisant, j'ai voulu démontrer que ceux que l'économie contemporaine identifie comme des créatifs le sont parce que leur rapport au monde est foncièrement «culturel», au sens élitiste et restreint, c'est-à-dire paradoxalement universel et ouvert, qui s'oppose au sens médiatique et fermé du terme. S'ils se frottent à l'art, à la culture et à ceux qui les font - et qui ne sont certes pas les gens du show bizz - c'est qu'ils savent obscurément qu'ils y trouveront une pédagogie de l'imaginaire, et donc les moyens de faire fonctionner le leur avec le plus d'efficacité et de plaisir possibles.

Quiconque m'aura suivi dans mes analyses et mes conclusions ne peut qu'en arriver à conclure que, loin d'être un loisir dont les gouvernements nationaux se sont dessaisis au profit des gouvernements municipaux pour qu'ils en fassent, au mieux, une attraction touristique, au pire une dépense à contrôler, la culture représente plutôt, malgré les apparences, le véritable moteur de toute croissance économique au siècle des communications et dans la société du savoir. Car s'il est vrai que nous échangerons désormais plus de services que de biens et plus de symboles que d'objets, alors notre capacité à dynamiser notre rapport au symbolique s'avèrera de plus en plus cruciale. Mais une culture municipale qui fonctionne sur l'archaïsme d'un penser petit — bouts d'asphalte, réductions insignifiantes de taxes, crispation sur l'utilitaire et l'immédiat ou, au contraire, extravagances kitsch de petitbourgeois prétentieux comme des tours ou d'autres pièces montées « de prestige » - ne peut tout simplement pas comprendre ce type de problématique.

S'il faut, dans cette perspective, louer le maire de Québec d'avoir mené la revitalisation du quartier Saint-Roch en jouant la carte de la bohème (ateliers d'artistes et divers espaces offerts à la créativité pour 
elle-même), on est obligé, du même souffle, de blâmer d'autres gouvernements municipaux dont l'attitude paternaliste, financière, utilitariste, arrogante, et pour tout dire parfaitement ignorante quant à la culture, risque fort de condamner les villes dans lesquelles ils sévissent à un déclin irrémédiable.

Malheureusement la ville de Saguenay, dont le maire et les élus ne pensent la culture qu'en termes de télévision ou de tourisme, fait partie du lot.

\section{Notes et références}

1 Jean-Pierre Vidal est professeur émérite au Département des arts et lettres de l'Université du Québec à Chicoutimi.

2 The Rise of the Creative Class, New York, Basic Books, 2002, p. 120. «Peut-être la seule ligne de démarcation significative est-elle celle qui sépare les organisations qui permettent à cette diversité de foisonner et celles qui ten- tent de la restreindre. Ces dernières courent le risque de perdre leur compétitivité parce qu'elles restreignent le bassin de talents créatifs où elles peuvent s'approvisionner. Les villes et les régions peuvent elles aussi perdre leur compétitivité si elles ne reflètent pas la nouvelle culture » (ma traduction).

3 Apparemment l'existence dans la ville étudiée d'une équipe de sport professionnel de haut niveau ne fait pas partie - contrairement à ce qu'on a voulu nous faire croire dans un débat récent concernant d'éventuels soutiens publics aux Expos de Montréal — des éléments attractifs puisque Pittsburgh, la ville de Florida, se classe assez bas, malgré ses glorieux Steelers, Pirates et autres Pinguins, équipes gagnantes, s'il en fût. À preuve, ajoute Florida, le déménagement de la célèbre et prospère entreprise de production de logiciels, Lycos, de Pittsburgh, sa ville natale, à Boston, autre ville certes bien pourvue, des Bruins aux Patriots en passant par les Celtics, d'équipes gagnantes, mais... qui ne possède pas que cela.

4 Raisons communes, Montréal, Boréal, 1995, p. 99. 